\title{
" Needle biopsy of the liver: A review
}

\author{
SHEILA SHERLOCK
}

\author{
From the Department of Medicine, Royal Free Hospital School of Medicine, London
}

Specimens of liver for pathological examination may be obtained during life either by open operation or by one of the various methods of percutaneous needle biopsy.

Needle biopsy has an interesting history. First employed by Paul Ehrlich in 1883 (quoted by Frerichs in 1884) in a study of the glycogen content of the diabetic liver, and in 1895 by Lucatello in Italy, it passed into general use in tropical medicine in the diagnosis of hepatic abscesses. In temperate climates the method did not achieve early popularity because of the undoubted risks involved. Just before and during the last war, however, there were many cases of non-fatal hepatitis which stimulated investigators to obtain hepatic material for histological study. Liver biopsy by the needle technique was reintroduced among others by Huard, May, and Joyeux (1935) in France, by Baron (1939) in the United States, by Iversen and Roholm (1939) in Denmark, by Axenfeld and Brass (1942) Germany, and by Dible, McMichael, and Sherlock (1943) in Britain. The elaboration of the technique, the clearer definition of indications and contraindications, the introduction of various safer needles, and especially the increase in the number of trained operators, has now resulted in needle biopsy being an accepted procedure in most large general hospitals. Because the method has now become so simple, this does not imply that it is always without risk. Needle biopsy should always be regarded as potentially fatal. Five hundred biopsies may be performed without incident only for the 501st to be complicated by massive intraperitoneal haemorrhage demanding immediate treatment. The patients must therefore be carefully selected and a real indication for it must be present before the biopsy is performed.

\section{SELECTION AND PREPARATION} OF THE PATIENT

The biopsy should only be performed in hospital and never undertaken on outpatients.

If the intercostal route is used, the patient must be cooperative and able to control his respiration voluntarily. A rent may otherwise be produced in the liver capsule. The method is therefore contraindicated in the confused or the unconscious.
Special care should be taken before biopsy is undertaken if there is spontaneous bruising or bleeding, especially if the patient is jaundiced. A one-stage prothrombin time test should always be performed. If the prothrombin time is prolonged, or even if it is normal but the patient is jaundiced, vitamin $K_{1}(10 \mathrm{mg}$. by injection) should be administered for three days. If factor V and VII deficiencies are suspected vitamin KS2 (Hoak and Carter, 1961) should be given parenterally. If the level is still increased by more than 2 seconds over the control and the patient is jaundiced the biopsy should not be performed. Prolongation of the one-stage prothrombin time in a patient with a normal serum bilirubin value and without a bleeding diathesis is not so serious, and if there are strong indications for the biopsy further tests of blood coagulation should be performed and if these are normal, biopsy can be undertaken. The platelet count should exceed 100,000 .

In every case, the patient's blood group should be known and 2 pints of compatible blood should be available. Blood transfusion facilities must be adequate in the event of complicating haemorrhage.

A mild sedative, such as $\mathbf{0 . 2} \mathrm{g}$. sodium amytal, is given 30 minutes before puncture.

If biopsy is required in the presence of ascites, this should be tapped. If this is not done the surface of the liver will float away from the tip of the biopsy needle and a specimen will not be obtained.

If the liver is small it may not be penetrated by the needle and distortion may result in puncture of the gall bladder or large blood vessels in the hilum. If there is doubt concerning the size of the liver, a plain radiograph of the abdomen should be a preliminary. If alterations in the position of the right diaphragm are suspected, a chest radiograph should be studied.

POSITION AND LOCAL ANAESTHESIA The patient lies supine with the right side as near the edge of the bed as possible. A firm pillow may be placed under the left side in the hollow of the body so that it is slightly tilted to the right. The right arm is placed behind the head and the patient looks to the left. After cleansing, the skin is anaesthetized with $2 \%$ procaine solution. A long $(8 \mathrm{~cm}$.), fine-bore needle is used to infiltrate the pleura and is then passed through the diaphragm to anaesthetize the peritoneum and the capsule of the liver. At least $5 \mathrm{ml}$. of local anaesthetic is needed. A preliminary nick is made in the skin with a scapula.

SITE OF PUNCTURE The intercostal technique is on the whole the more satisfactory for it provides the whole 
transverse depth of the right lobe for the puncture; intra-abdominal viscera are avoided. It does, however, involve puncture of the pleural cavity. The site chosen is the eighth, ninth, or tenth intercostal space in the mid or anterior axillary line. The place must be the point of maximum dullness to percussion.

The subcostal technique is confined to livers enlarged at least $6 \mathrm{~cm}$. below the right costal margin or in those in patients with disease of the right chest. It has the advantage that a specific lesion on the surface of the liver may be aimed at and punctured. Otherwise the site chosen is below and to the right of the xiphoid process in the midclavicular line, the needle being directed to the right and cephalically.

\section{TECHNIQUE OF PUNCTURE}

The biopsy may be obtained either by techniques involving predominantly aspiration such as the Iversen and Roholm (1939) or Menghini (1958) techniques or by predominantly a puncture procedure such as the Vim-Silverman method (Schiff, 1951). All three give good results in experienced hands. The technique chosen varies with the individual. The method should be undertaken only by those well trained in its execution. The novice should certainly practice on the cadaver before attempting it on the patient and should learn under the supervision of an expert. Serious complications increase in inexperienced hands. The aspiration of blood from the liver should not occasion alarm.

IVERSEN AND ROHOLM METHOD (Sherlock, 1945) The instrument used is a handled trocar and cannula modified from an antrum puncture needle. It is $15 \mathrm{~cm}$. long and $1.7 \mathrm{~mm}$. diameter. The needle is passed through the skin but not through the diaphragm and the patient is then instructed to 'take a deep breath in, let it out and then hold your breath'. This displaces the lung upwards and ensures apposition of diaphragmatic and costal pleura. The trocar and cannula are now pushed through the diaphragm into the right lobe of the liver. The trocar is not withdrawn until the instrument is fully a centimetre inside the liver substance. The cylinder of liver tissue is then punched out by pushing the cannula on a further 3 to $5 \mathrm{~cm}$. A $20 \mathrm{ml}$. syringe is connected to the cannula and suction is applied and maintained while the cannula is withdrawn. The puncture wound in the skin is sealed with collodion. The fragment of liver is usually found in the barrel of the syringe. Occasionally it remains in the cannula.

MENGHINI 'ONE-SECOND' NEEDLE BIOPSY (Menghini, 1958; Norris, Singh, and Montuschi, 1958). The needle used is made in three diameters, 2, 1.6, and $1 \mathrm{~mm}$. (Figs. 1 and 2). We use the $1.6 \mathrm{~mm}$. one routinely and reserve the smallest for poor-risk patients, for instance for those in deep jaundice, where intraperitoneal haemorrhage is possible. The tip of the needle is oblique and slightly convex toward the outside. This results in an excellent cut of the biopsy specimen without any need to rotate the needle as the biopsy is performed. The needle also has fitted within its shaft a blunt nail $3 \mathrm{~cm}$. long, and $0 \cdot 2 \mathrm{~mm}$. diameter

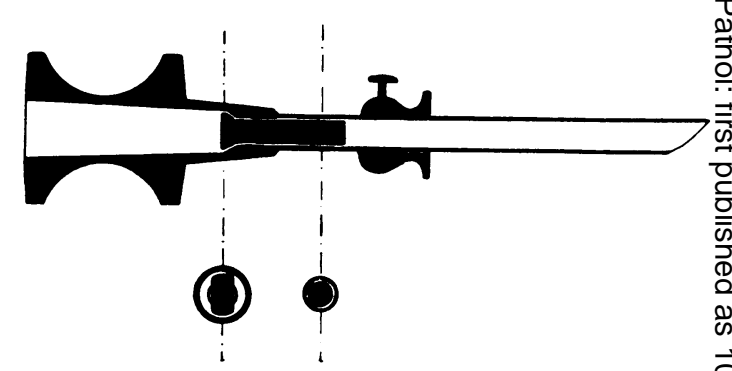

FIG. 1. Longitudinal section of the Menghini liver biopsyneedle. Note nail in the shaft of the needle.

From Menghini, 1958.

smaller than the internal diameter of the cannula. Thecer diameter of the flattened head of the nail is larger thant that of the cannula and also than that of the internal diameter of the insertion of the aspirating syringe. $\overrightarrow{-}$ This prevents the nail from falling into the cannula and음 also from being aspirated into the syringe. This internalblock prevents the biopsy from being fragmented or distorted by violent aspiration into the syringe and regulates the force of aspiration.

The syringe and needle are assembled and $3 \mathrm{ml}$. of sterile saline drawn into the syringe. The needle is then inserted through the anaesthetized track down to but not through the intercostal space and $2 \mathrm{ml}$. solution injected to clear the needle of any skin fragments. Aspiration is now begun and maintained. This is the slow part of the procedure. With the patient holding his breath in expiration, the needle is rapidly introduced perpendicular to the skin into the liver substance and을 extracted. This is the quick part of the procedure. Rotation is not performed. The tip of the needle is now placed under saline in a flat-bottomed glass receptacle and only now is aspiration stopped. It may be necessary gently to inject a little of the remaining saline from the? syringe to free the biopsy.

This method has the advantage that the needle is very. briefly in the liver, only slightly more than the "one응 second' claimed by the originator; this increases the safety. The method is also extremely easy to perform.을 Discomfort to the patient is less than that experienced $\rightarrow$ with other techniques. The instrument is simple ando therefore not costly. The main disadvantage is that in the presence of fibrosis the failure rate is high and the $N$ specimen obtained may be small. Menghini has now $\mathrm{N}$ performed his method on more than 2,000 occasions? without fatality.

VIM-SILVERMAN METHOD The instrument consists of aco short trocar and cannula which are introduced into the liver. The trocar is removed and the biopsy is punched out $\stackrel{?}{?}$ by the introduction of a longer cannula split longitudinally, $\square$ both halves of which tend to spring apart. The short $\overline{0}$ cannula is then advanced until the tips of both are level. The apparatus is rotated to break off the end of the $\frac{O}{\mathbb{D}}$ biopsy and withdrawn. Suction is not necessary. This 2 method has a high success rate in the presence of cirrhosis, The sample is large but distortion is often gross. 
Wagner, Picou, and Yakovac, 1959) or the Menghini (Hong and Schubert, 1960) techniques may be employed. The Menghini may be the better for it is the quicker. In infants local anaesthesia, with 15 to $60 \mathrm{mg}$. pentobarbital 30 minutes before the biopsy, is adequate. The child is restrained by adhesive strapping across the upper thighs and chest and the subcostal approach used (Kaye et al., 1959). If the liver is small when the intercostal route is employed the assistant compresses the chest at the end of expiration to arrest respiration (Hong and Schubert, 1960).

Liver biopsy is particularly useful in investigating patients with neonatal jaundice when clinical features are equivocal and biochemistry of little help. An unnecessary laparotomy, particularly undesirable in a baby with hepatitis, may be prevented. In four patients with neonatal jaundice, a diagnosis was made by this means at $3,6,8$, and 8 weeks of life respectively (Kaye et al., 1959).

In older children general anaesthesia is generally preferred, depending on the cooperation of the child. If splenic venography is necessary, the two procedures can be performed under the same anaesthetic (Shaldon and Sherlock, 1962).

\section{RISKS AND COMPLICATIONS}

In a recent review of 20,016 needle biopsies of the liver the mortality was stated to be $0 \cdot 17 \%$ (Zamcheck and Sidman, 1953; Zamcheck and Klausenstock, 1953) and deaths from haemorrhage were usually in those patients with a hopeless prognosis.

PLEURISY AND PERIHEPATITIS A brief friction rub caused by fibrinous perihepatitis or pleurisy may sometimes be heard on the next day. It is of little consequence and pain subsides with analgesics. A chest radiograph sometimes shows a small pneumothorax.

HAEMORRHAGE Bleeding from the puncture wound usually consists of a thin trickle lasting 10 to 60 seconds and the total blood loss is only 5 to $10 \mathrm{ml}$. Serious haemorrhage is usually intraperitoneal but may be intrathoracic from an intercostal artery. In one series significant haemorrhage occurred 16 times in 7,532 biopsies $(0 \cdot 2 \%)$. Laparotomy was required in four instances, transfusion alone in three, and expectant treatment was successful in nine (Terry, 1952). The bleeding results from perforation of distended portal or hepatic veins or aberrant arteries. In some cases a tear of the liver follows deep breathing during the intercostal procedure. Severe haemothorax usually responds to blood transfusion and chest aspiration. Haemorrhage is extremely rare in those not jaundiced. It is most common in severe hepatocellular disease and where this is suspected, biopsy should be avoided. Patients with obstructive jaundice after vitamin $\mathrm{K}$ therapy tolerate liver biopsy well.
BILIARY PERITONITIS Using the intercostal approach the gall bladder should be avoided. There are, how은 ever, seven reports of this complication in the literature, usually in patients with an anatomicaf abnormality of the liver (Madden, 1961). The resultant biliary peritonitis may require surgica氖 drainage.

A large bile duct in the liver may be punctured in patients with extrahepatic cholestasis. This has led"s to liver biopsy being contraindicated in patients 5 with obstructive jaundice. In my experience this is $\dot{a}$ very small risk and the puncture usually seals itself off.

However, occasionally an infected biliary peri? tonitis may develop in patients with cholangitiser (Terry, 1952). I have never seen this happen althought occasionally patients with cholangitis have a rigoro and pyrexia after biopsy. Liver material from these patients grows coliform bacilli and histology shows? an acute cholangitis.

PUNCTURE OF OTHER VISCERA This is very rare. The colon may be inadvertently biopsied (Baron, 1939) or the kidney but this is not usually dangerous.

\section{RELIABILITY OF NEEDLE BIOPSIES} AS REPRESENTATIVE

It is perhaps surprising that such a small biopsy should so often be representative of changes in the whole liver. The lesions of cholestasis, steatosis virus hepatitis, and the reticuloses are fortunately diffuse. This is also true of most cirrhoses, although? in the coarsely nodular liver of post-necrotic cirrhosis it is possible to aspirate a large nodule and find the architecture normal (Braunstein, 1956). The focal granulomatous diseases, such as sarcoidosis, tumour deposits, and abscesses, may be missed but5 this is surprisingly infrequent. In a recent comparison of the results of needle biopsy compared with? operative biopsy there was complete agreement ino $76.9 \%$, minor differences in $16.1 \%$, and in only $7 \%$ did needle biopsy completely miss the lesiono (Federlin and Sandritter, 1961). Liechty (1958), on the other hand, reports $40 \%$ positive diagnoses withn the needle method compared with $98.3 \%$ using openo biopsy. Most authors, however, comment on the increase in fibrous tissue under the capsule in operative biopsies which gives a false impression of the liver as a whole (Popper and Schaffner, 1957; Sherlock, 1958). Also operative biopsies may showo artefactual changes such as patchy loss of glycogen $\overrightarrow{\mathbb{D}}$ haemorrhages, and polymorph infiltration, all due toक्ठ the effects of the operation and of the anaesthetic

The combination of peritoneoscopy with needle liver biopsy enables the surface of the liver to beo 
visualized and the biopsy taken directly from any focal abnormality (Becker, 1961; Samuelsson and Sjöstedt, 1961). More than one biopsy may be taken. The specimen is subcapsular and may therefore be fibrotic and again not representative of the interior of the liver. In experienced hands such as those of Caroli, Mainguet, and Ricordeau (1961) in France, or Kalk and Wildhirt (1962) in Germany, peritoneoscopy adds little to the time taken or to the discomfort involved. With less practised operators, however, the increase in extent of the procedure does not compensate for the information obtained.

\section{NAKED-EYE APPEARANCES}

A satisfactory biopsy is 1 to $4 \mathrm{~cm}$. long and weighs 50 to $200 \mathrm{mg}$.

The cirrhotic liver tends to crumble into fragments of irregular contour. The fatty liver has a pale, greasy look and floats in the formol saline fixative. The liver containing malignant deposits is a dull white. The liver from a patient with Dubin-Johnson hyperbilirubinaemia is diffusely chocolate coloured (Fig. 3).

Terry (1954) emphasized the value of detailed examination of the biopsy. In cholestatic jaundice, the greenish central areas contrast with the less green periphery of the lobule. Transillumination may show up granulomata, for instance, in sarcoidosis or tuberculosis as translucent areas. The vascular centres of lobules in hepatic congestion may be obvious.

\section{FIXATION AND PREPARATION OF SPECIMEN}

The specimen is less likely to fragment, and easier to cut in one plane, if it is laid on a strip of blotting paper before placing in $10 \%$ formol saline. The receptacle used should be a wide-mouthed one so that it is easily introduced and removed. The biopsy is processed in the usual way on a Histokine automatic preparative machine using a 21-hour cycle and including formol mercury as a post-fixative. After embedding in paraffin, sections are cut of $5 \mu$ thickness.

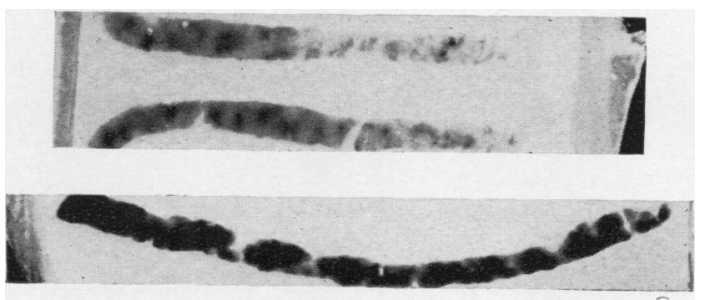

FIG. 3. Paraffin blocks of needle liver biopsies from a normal patient and (below) the chocolate coloured biopsy of a patient with Dubin-Johnson hyperbilirubinaemia.
Haematoxylin and eosin and reticulin by a silver method are routine stains, and to most sections Perls stain for iron and periodic-acid-Schiff for glycogen are also applied.

Serial sections are important for the diagnosis of lesions which may be scattered through the liver.

\section{INDICATIONS FOR NEEDLE BIOPSY AND HISTOLOGICAL APPEARANCES}

NORMAL APPEARANCES The portal zones bear a regular relation to the central areas. This may be difficult to establish in small biopsies, especially if no portal zones have been obtained, but this orientation is an essential preliminary before reporting the biopsy. Each portal zone consists of one or two bile ductiles, a branch of the hepatic artery and one of the portal vein, a few mononuclears, and an occasional fibroblast. The liver cell plates are one cell thick and contain abundant glycogen. Mitoses are not seen in the liver cells, which are usually mononucleate and of regular size. The sinusoids are lined by Kupffer cells and can be seen converging upon the central vein.

JAUNDICE Acute jaundice rarely merits liver biopsy for clinical observation and biochemical methods will usually make the diagnosis certain. The method carries extra risk in this group.

Acute virus hepatitis In acute virus hepatitis (Fig. 4) the lobular pattern is usually maintained intact, although if necrosis is massive the reticulin collapses (Dible et al., 1943). The portal zones show a widening composed mainly of mononuclears, polymorphs, and eosinophils, fibroblasts, and proliferating bile ducts having a slit-like lumen. This portal lesion is very prominent and some cellular infiltration and scarring may be observed for months after apparent clinical recovery. The sinusoids are infiltrated with mononuclears. Hepatocellular necrosis is maximal in the centrizonal areas. Focal eosinophilic necrosis with acidophilic bodies in the liver cells may also be seen. Bile thrombi, maximally centrizonally, are noted, especially in the Kupffer cells and liver cells.

Cholestatic jaundice In cholestatic jaundice the constant characteristic feature is a normal lobular architecture with bile retention, maximal centrizonally in bile canaliculi, liver cells, and in Kupffer cells. The extent of the bile retention depends on the depth of jaundice and the duration, and bile plugs persist for some time after the jaundice fades. Mild patchy necrosis and nuclear changes may be seen in the centrizonal liver cells.

Imposed on these background features are certain changes, mainly in the portal zones, which depend 


\section{Jaundice}

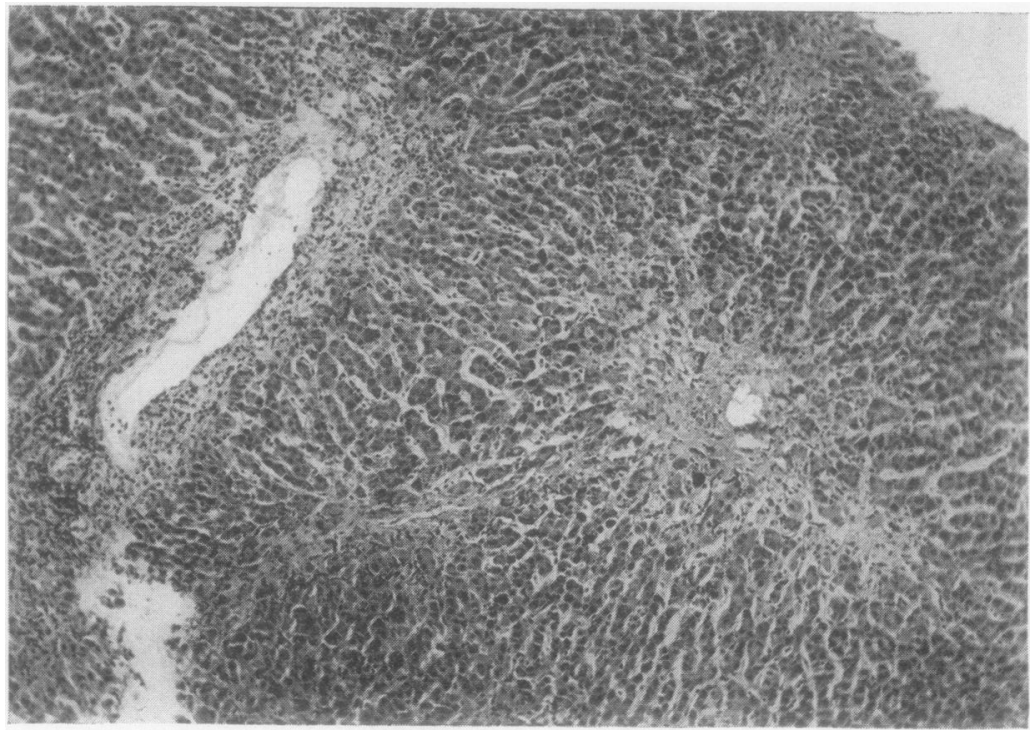

FIG. 4. Acute virus hepatitis. The centrizonal area shows loss of liver cells. The portal zone is heavily infiltrated with mononuclears and this cellular infiltration extends through the sinusoids towards the central vein. The general architecture of the liver is maintained intact. Stained haematoxylin and eosin $\times 75$.

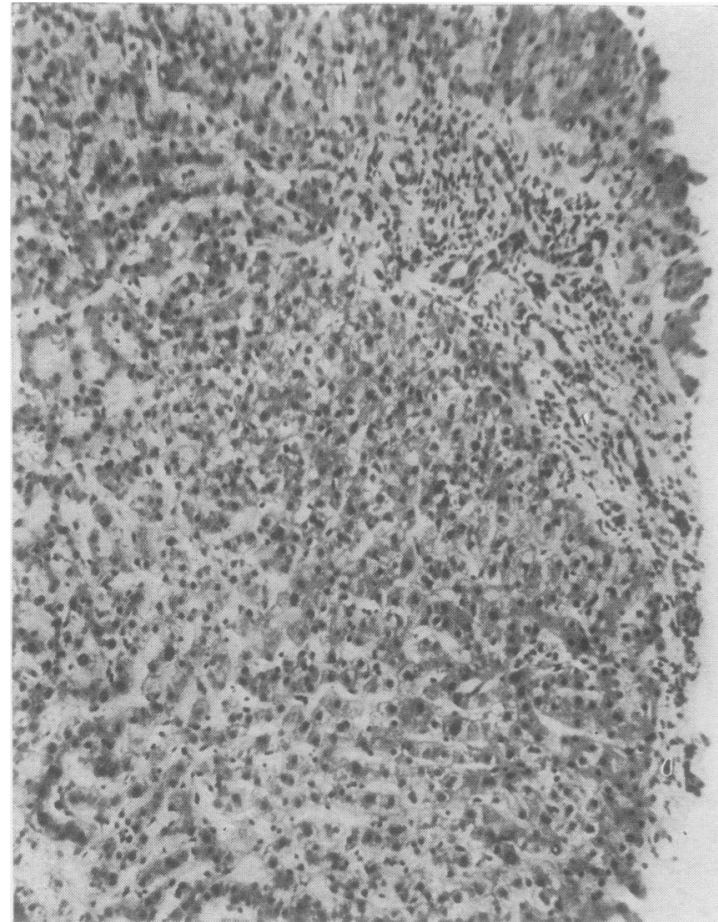

FIG. 5

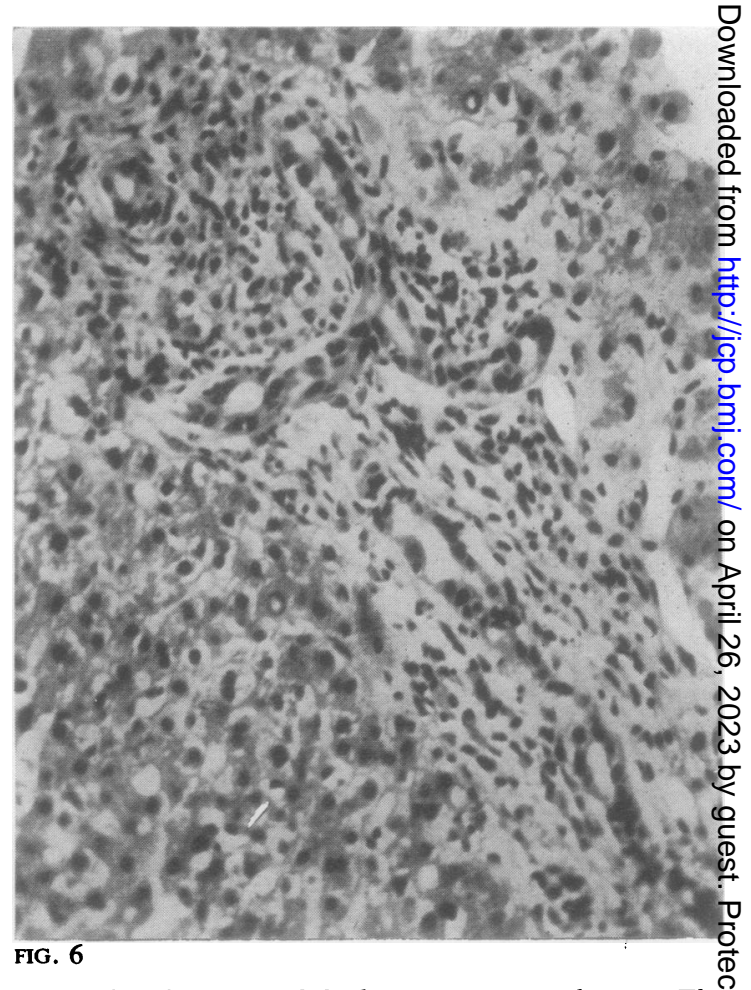

$\stackrel{\overrightarrow{\mathrm{D}}}{\stackrel{\mathrm{C}}{\mathrm{D}}}$

FIG. 5. Extrahepatic biliary obstruction due to gall stones. The zonal architecture of the liver is maintained intact. Theते portal zones show expansion and contain proliferating bile ducts, fibrosis, and cells. The centrizonal area shows heavy bile accumulations in liver cells and bile canaliculi. Surrounding liver cells show variation in size and in nuclei. Stained haemato $x y l i n$ and eosin $\times 72$.

FIG. 6. Same case as Fig. 5. The expanded irregular portal zone shows numerous proliferated bile ducts some of thene having a wide lumen. The cellular infiltrate is mononuclear with many polymorphs, especially around the dilated bile ducts Stained haematoxylin and eosin $\times 275$. 


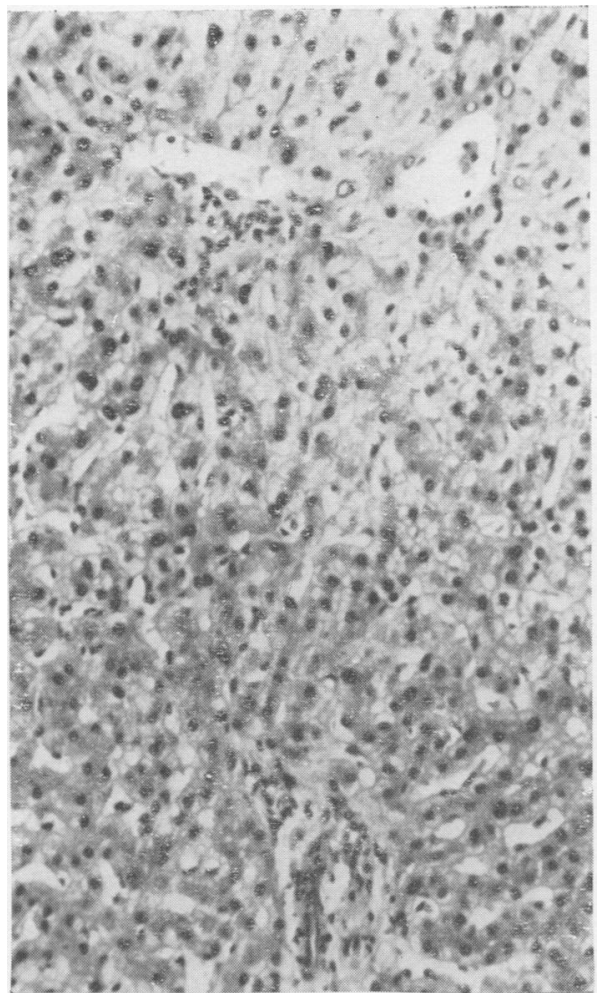

FIG. 7

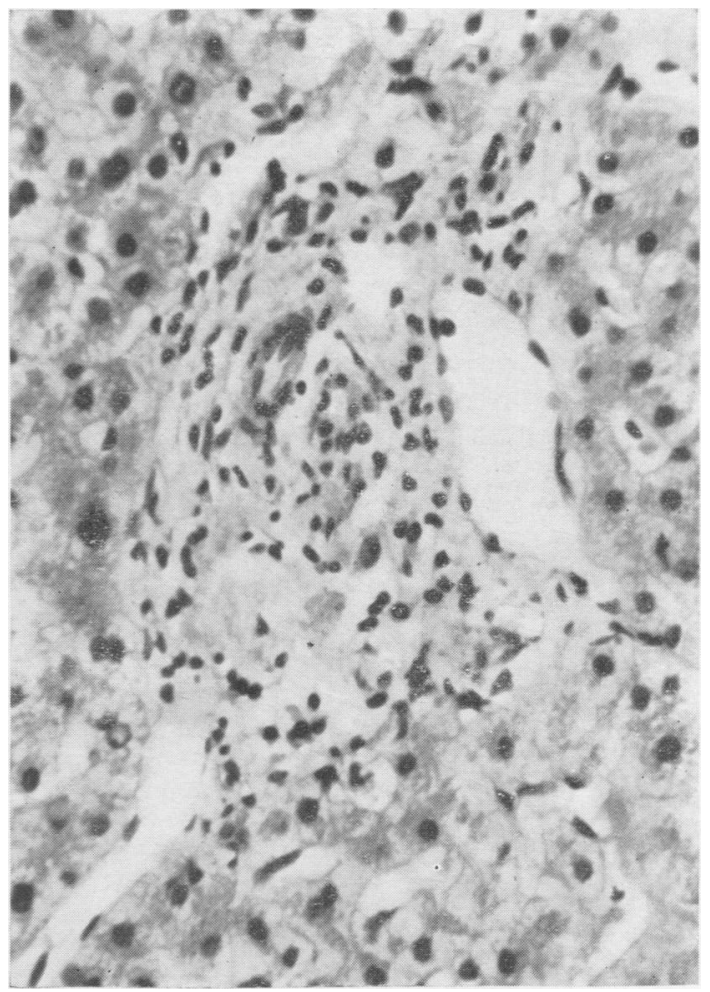

FIG. 8

FIG. 7. Cholestatic jaundice following chlorpromazine. The zonal architecture is maintained intact. The centrizonal area shows heavy bile stasis. Liver cells, especially centrizonally, show patchy, often feathery, necrosis with evidence of regeneration shown by variation in cell and nuclear size. The portal zones are virtually normal. Stained haematoxylin and eosin $\times 72$.

FIG. 8. Same case as Fig. 7. Portal zone shows a slight increase in cellularity, mainly mononuclear. A few eosinophils could also be demonstrated. Stained haematoxylin and eosin $\times 275$.

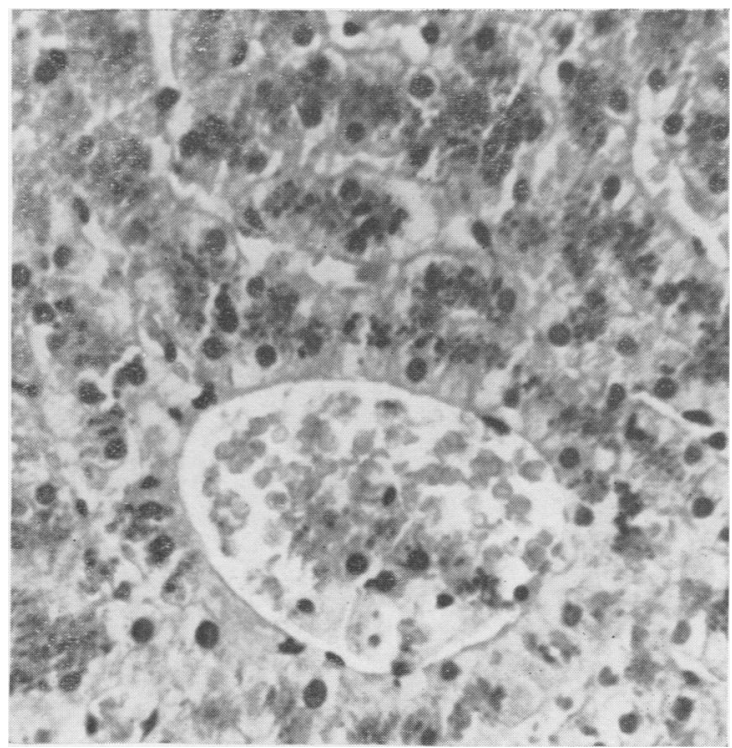

FIG. 9. Dubin-Johnson hyperbilirubinaemia. The liver cells and Kupfer cells, especially centrizonally, are packed with a dark pigment which gives the staining reactions of a lipofuscin. Stained haematoxylin and eosin $\times 275$. 
on whether the jaundice is of intrahepatic or extrahepatic origin. The essential difference in the liver between extra- and intrahepatic biliary obstruction is the dilatation of bile ducts in the one and not in the other. This may proceed in extrahepatic cholestasis to rupture of small ducts within the liver and the production of so-called 'bile lakes' or 'bile necroses' which are diagnostic of a block in large bile ducts. Unfortunately, these are not constantly seen. Reduplication of bile ducts having a wide lumen and sometimes containing bile is a feature of extrahepatic cholestasis (Fig. 5 and 6). Invasive fibrosis in the portal zones with predominant polymorph infiltration also suggests extrahepatic cholestasis.

In intrahepatic cholestasis due to virus hepatitis, necrotic changes in the liver cells are prominent and the histological picture is usually diagnostic (Shaldon and Sherlock, 1957).

In intrahepatic cholestasis due to drugs of the chlorpromazine type (Fig. 7 and 8 ) the portal zones show mild cellular infiltration, mainly histiocytic, but in the early stages eosinophils may be prominent. Liver cell damage tends to be more prominent, with feathery degeneration and ballooning of cells, peripheral vacuolation, and hyaline deposits. Focal necrosis of liver cells may be seen. Anisocytosis of liver cells and mitoses are frequent (Read, Harrison, and Sherlock, 1961).

In intrahepatic cholestasis due to drugs of the methyl testosterone or norethandrolone type the portal zones are normal (Schaffner, Popper, and Chesrow, 1959).

Hepatic histology cannot be relied upon to differentiate with certainty cholestasis of intrahepatic from that of extrahepatic origin (Popper and Schaffner, 1959).

Haemolytic jaundice In haemolytic jaundice, hepatic histology is normal apart from increased iron deposits in Kupffer and liver cells.

Congenital hyperbilirubinaemias In the usual Gilbert variety hepatic histology is normal (Krarup and Roholm, 1941). In the Dubin-Johnson type (Dubin, 1958) the liver cells are filled with a brown pigment believed to be a lipofuscin, 'black liver jaundice' (Fig. 9).

THE CIRRHOSES Needle biopsy is not necessary in the patient with advanced cirrhosis in whom diagnosis is quite obvious clinically. It is useful in recognizing well-compensated cirrhosis as a cause of hepatomegaly or splenomeagaly or to obtain a baseline before some treatment, such as with corticosteroids, is begun.

Cirrhosis is an anatomical diagnosis which should be confined to lesions showing the following characteristics (Report on the classification and $\frac{\text { Fै }}{\vec{\sigma}}$ nomenclature of cirrhosis of the liver, 1956).

1 All parts of the liver must be involved, although not necessarily each lobule; this allows the inclusiono of the post-necrotic type in which large nodules oftent contain one or more intact lobules.

2 Hepatocellular necrosis must be present at疋 some stage; this allows the inclusion of cirrhosiso which, at the time of histological examination, does not show damage to hepatic cells.

3 Nodular regeneration must be present. Fibrous tissue bands join central veins with portal tracts ando so disorganize the normal hepatic architecture.

The biopsy from the cirrhotic liver is liable to be small and fragmented and it may be very difficult, ${ }^{\mathcal{B}}$ not only to be certain that the normal architecturen is lost, but also to differentiate between a fine 'portal' cirrhosis and a coarse 'post-necrotic' one.o The term cirrhosis should never be used synonymously with fibrosis.

Cirrhosis of the alcoholic is invariably fatty and in the acute stage focal necrosis of liver cells with surrounding polymorph reaction may be seen (Fig. 13). The hyaline deposits in liver cells described by Mallory are best demonstrated by the phos? photungstic-acid-haematoxylin method or by luxo fast blue when the hyaline stains dark purplish bluẹ (Becker and Treurnich, 1959). They are not specific for alcoholism (Popper, Rubin, Krus, and Schaffner 1960). In the alcoholic, various stages short of cirrhosis, usually stellate fibrosis may be noted and the cellular reaction may also be extremely acute (Beckett, Livingstone, and Hill, 1961).

An increasing number of patients, usually but no쭁 necessarily young, and women rather than men:with an acute 'juvenile' cirrhosis are being seen. The patients are usually jaundiced and show high serumb gamma globulin values. An autoimmune process in the liver has been postulated and L.E. cells mayo sometimes be found in the blood (Mackay, 1961) The condition may in some instances be initiated byㅡㅡ. acute virus hepatitis. Liver biopsy shows a very active cirrhosis of post-necrotic type with isolation? of groups of liver cells by young fibrous tissued (Fig. 10). The liver cells may be giant, multinucleate $\mathrm{w}_{\mathrm{w}}$ or form rosettes. The biopsy is heavily infiltratedo with lymphocytes and plasma cells (Fig. 11).

Haemochromatosis may be suspected by the browr pigment seen in the liver in haematoxylin and eosir? stained sections. The presence of excess iron shouldo always be confirmed by Perls' reaction. Siblings of̄ patients with haemochromatosis may show in creased amounts of iron in the liver (Williams andi Scheuer, 1962) and this should always be considerefo in a patient who shows unsuspected iron deposition. Study of 558 consecutive liver biopsies showe 


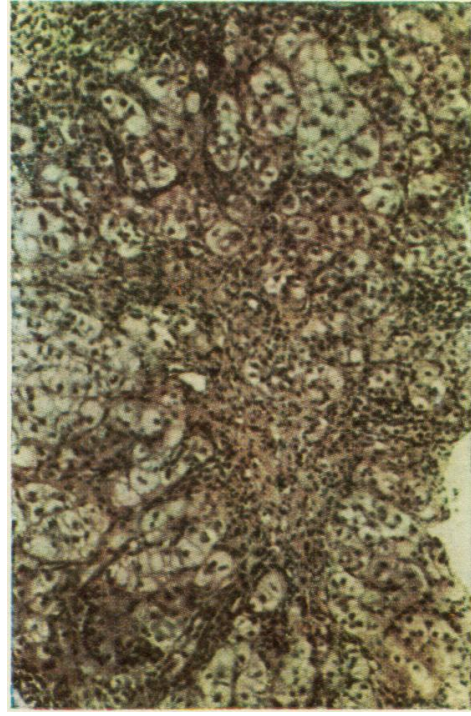

FIG. 10

FIG. 10. Acute 'juvenile' cirrhosis. The lobular architecture is completely disturbed. Isolated groups of liver cells, which often assume a rosette-like appearance, are separated by the septa of connective tissue. Remaining cells are large with clear cytoplasm. Lymphocytic and plasma cell infiltration is conspicuous. Stained haematoxylin and eosin $\times 40$.

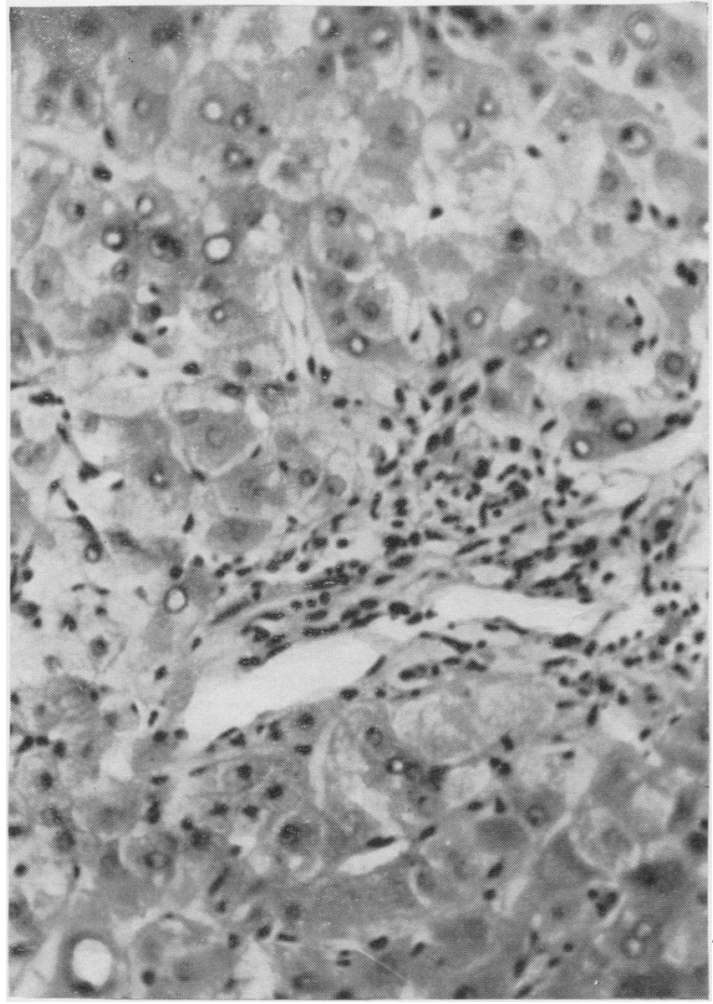

FIG. 12. Hepatolenticular degeneration (Wilson's disease). Liver cells adjoining a fibrous tissue band show gross vacuolation of their nuclei (glycogenic degeneration) and occasionally fatty change. Haematoxylin and eosin $\times 165$.
FIG. 11. Same case as Fig. 10. Reticulin stains confirm the isolation of liver cells by bands of fibrous tissue. $\times 120$.

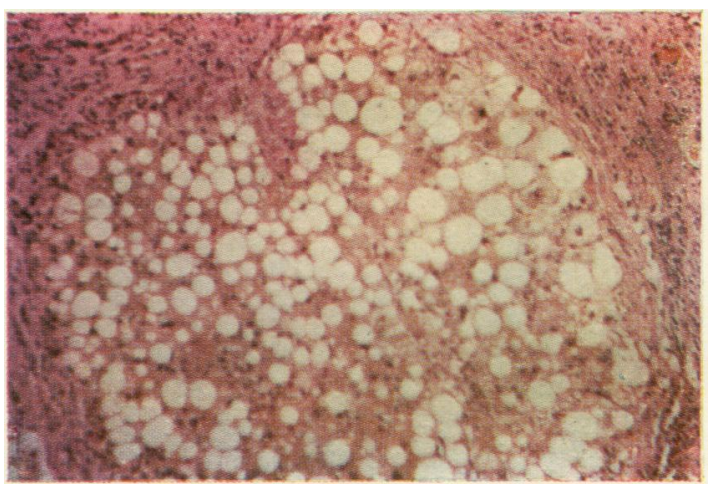

FIG. 13. Cirrhosis of the alcoholic. The picture is of a fine portal type cirrhosis. Liver cells show gross fatty change and fatty cysts are sometimes seen. Foci of inflammatory cells are scattered through the parenchyma. Stained haematoxylin and eosin $\times 120$.

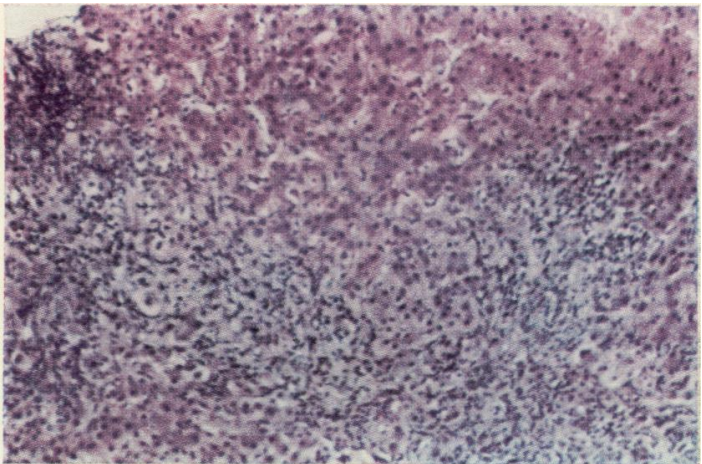

FIG. 14. Primary biliary cirrhosis. The lobular pattern is grossly disturbed by fibrous bands which extended from the portal zones. The fibrous septa contain aggregations of lymphocytes. Stained haematoxylin and eosin $\times 40$. 
significantly a higher proportion of iron in those with hepatic disease $(44 \%)$ than in those without significant disease (Zimmerman, Chomet, Kulesh, and McWhorter, 1961).

Wilson's disease Hepatolenticular degeneration (Wilson's disease) should be considered in any patient with cirrhosis presenting under 30 years old even if there are no abnormal neurological changes. Fatty change and peripheral nuclear vaculation of the liver cell (Fig. 12) in a young patient with postnecrotic cirrhosis is very suggestive (Anderson and Popper, 1960). If this diagnosis is being considered a small portion of the liver biopsy should be fixed immediately in a freshly prepared solution of rubeanic acid in $70 \%$ alcohol when the copper is seen in sections as brownish-black granules in the liver cells (Uzman, 1957).

Biliary cirrhosis Patients with prolonged cholestasis, whether intrahepatic or extrahepatic, ultimately develop biliary cirrhosis. There is characteristically a widening of the portal areas by fibrous tissue which encroaches on the lobules and sends septa into the parenchyma. Nodular regeneration is never so prominent as in other forms of cirrhosis. In the later stages, difficulties may arise in differentiating this from other types of cirrhosis.

Secondary biliary cirrhosis follows prolonged extrahepatic biliary obstruction often due to traumatic stricture. If the biopsy is taken during an episode of cholangitis Gram-negative organisms may be cultured from it and this should always be attempted in such patients. Polymorphs are conspicuous in the portal zones where bile ducts are proliferating widely.

In primary biliary cirrhosis the aggressive infiltrating fibrosis in the portal zones is particularly marked and bile ductules are inconspicuous (Fig. 14). Lymphocytes may form foci and plasma cells may be obvious. However, the picture of primary biliary cirrhosis may be very difficult to distinguish from secondary biliary cirrhosis in the individual case (Sherlock, 1958).

HEPATIC TUMOURS Although Fisher and Faloon (1958) believed that needle biopsy was particularly hazardous in the presence of metastatic malignancy, the mortality of their series being $12 \%$, others state that the risk is no greater than in other patients (Parets, 1959; Fenster and Klatskin, 1961), and this has been my own experience. The chance of obtaining a positive biopsy increases the greater the size of the liver. The percentage of positive biopsies in recent large series has been 64 to 78 (Ward, Schiff, Young, and Gall, 1954; Parets, 1959; Nelson and Salvador, 1960; Fenster and Klatskin, 1961). If a cylinder of tissue is not obtained, it is worth centri-

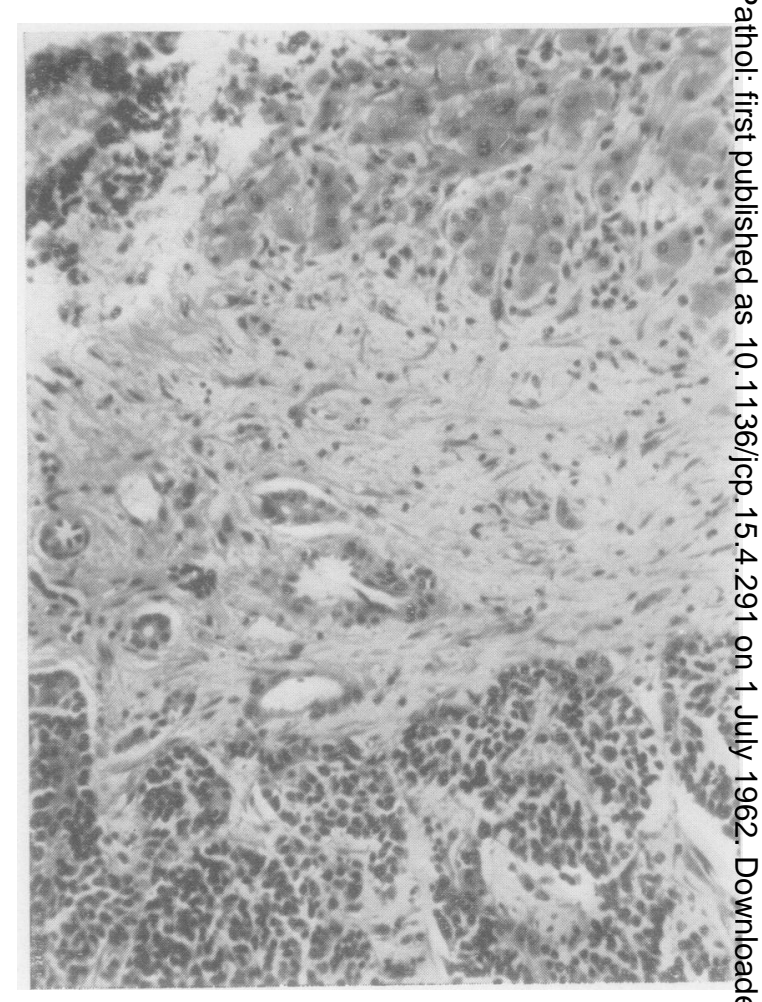

FIG. 15. Hepatic metastasis from primary in bronchus. $A \stackrel{\Phi}{\AA}$ the top of the section relatively normal liver tissue car $\overrightarrow{5}$ be seen infiltrated by mononuclear cells. The metastasis is separated by a zone of fibrous tissue. The malignant cells are undifferentiated. Stained haematoxylin and eosin 120.

fuging any debris or blood clot and examining it fo흠 malignant cells. Study of sections will not alway. enable the site of the primary to be detected especially if the tumour is undifferentiated (Fig. 15)음

THE RETICULOSES Care must be taken not to attempto to biopsy if there is any bleeding tendency.

In Gaucher's disease the typical Gaucher cell map

be readily shown in the liver.
It is rare for liver biopsy to help in the diagnosis of multiple myeloma.

The liver is involved in about $70 \%$ of patients with Hodgkin's disease (Levitan, Diamond, and Craver, 1961) and it is therefore worthwhile peren forming liver biopsy where histological proof cannot otherwise be obtained. A positive result is, however $\overrightarrow{-}$ not constant and in one series none of 10 patient. with Hodgkin's disease gave a positive liver biopsy although in all the liver was at necropsy shown to be involved (Amos and Goodbody, 1959). In another series, eight of 12 patients with leukaemia and five 
of 30 with other lymphomas gave positive results (Nelson and Salvador, 1960). In many instances, the picture is a non-specific one of mononuclear infiltration in the portal zones. When the result is positive, the Hodgkin's or leukaemic tissue is maximal in the portal zones, and in myeloid leukaemia immature cells of the white cell series can be seen crowding the sinusoids.

In the myeloproliferative disorders, liver biopsy may show sinusoidal infiltration by multinucleated cells resembling megakaryocytes, discrete sinusoidal foci of haemopoietic tissue, or diffuse infiltration by primitive myeloblast-like cells (Amos and Goodbody, 1959).

GRANULOMAS OF THE LIVER The granuloma is a miliary lesion comprising central amorphous debris surrounded by a zone of epithelioid cells with or without giant cells, lymphocytes, and fibrous tissue (Fig. 17). It is non-specific and the observation of such a lesion in a liver biopsy section is diagnostic of a granulomatous disease but not of any specific one.

If granulomatous disease is suspected, and the first sections give negative results, serial sections must be examined from the entire biopsy.

A granulomatous lesion will be found in the liver in $60 \%$ of patients with sarcoidosis but there must be a compatible clinical picture and the Kveim test should also be performed (James, 1961).

If miliary tuberculosis is suspected, the biopsy should also be cultured (Healey, Leff, and Rosenak, 1959) and Ziehl-Neelsen stains should be applied. The centre of the granuloma may show caseation. In a series of 64 biopsies on patients with tuberculosis, $11 \%$ showed miliary granulomata (Singh, Jolly, and

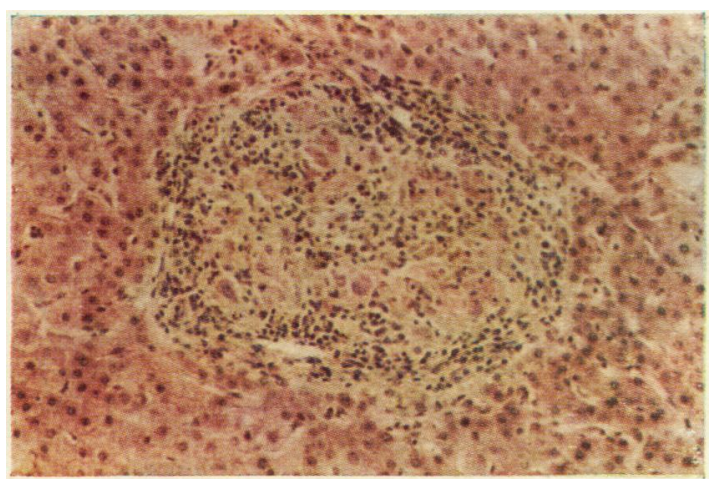

FIG. 16. Sarcoidosis. A well-demarcated granuloma is seen with surrounding lymphocytes and central, palestaining epithelioid cells. Stained haematoxylin and eosin $\times 84$.
Singh, 1960) and in another $80 \%$ of 30 patients with extrapulmonary tuberculosis, gave positive liver biopsies (Korn, Kellow, Heller, Chomet, and Zimmerman, 1959). Miliary granulomas may be found in the liver after B.C.G. vaccination (Camain, Sénécal, and Couturier, 1956).

In brucellosis, granulomata may be scattered throughout the liver. The lesions tend to be smaller than in sarcoidosis and less clearly demarcated. Both Br. abortis (Cohen, Robins, and Lipstein, 1957) and Br. melitensis (Fogel and Lewis, 1960) have been cultured from liver biopsy specimens.

Hepatic granulomata may also be seen in lepromatous leprosy and acquired secondary syphilis. Similar lesions are seen in histoplasmosis (Parsons and Zarafonetis, 1945) and in coccidioidomycosis (Ward and Hunter, 1958), and in both conditions appropriate stains for the organism should be applied and the biopsy should be cultured.

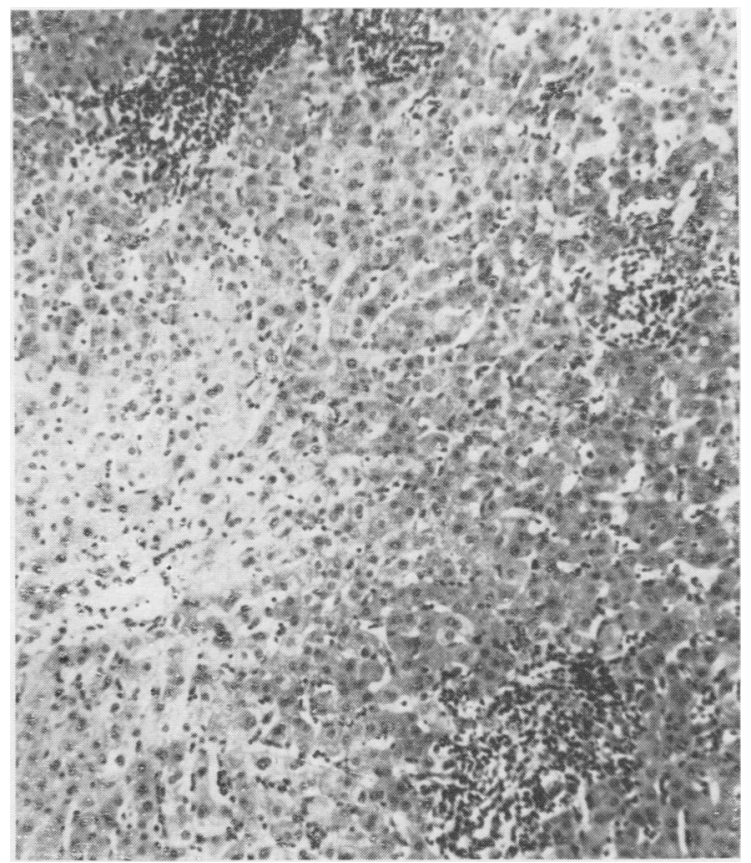

FIG. 17. Pyogenic liver abscess secondary to suppurative appendicitis. The portal zones show a dense infiltration with cells, mainly polymorphonuclear. Stained haematoxylin and eosin $\times 75$.

INFECTIONS Accumulations of polymorphs in the portal zone may be found near a pyogenic liver abscess (Fig. 17). If this diagnosis is suspected, the 
biopsy should be stained by Gram's method and a small portion cultured.

In leptospira icterohaemorrhagica infection, the liver biopsy shows focal necrosis and periportal infiltration with histiocytes and polymorphs. The leptospira can sometimes be demonstrated and cultures may reveal the organism (Ostertag, 1950).

In hepatic amoebiasis, the changes are usually non-specific with polymorph and monocytic infiltration of the portal zones. Small abscess cavities may be punctured.

Suspected hydatid disease is a contraindication to needle biopsy as this may lead to fatal anaphylaxis or peritoneal dissemination.

METABOLIC DISORDERS A death has been reported following liver biopsy in a patient with advanced amyloidosis (Volwiler and Jones, 1947) and it is believed that the liver may be easily split by the biopsy needle in this condition. In another series, intraperitoneal haemorrhage was found in one of 18 patients with amyloidosis after liver biopsy (Stauffer, Gross, Foulk, and Dahlin, 1961). In my experience, the risk of haemorrhage is no greater

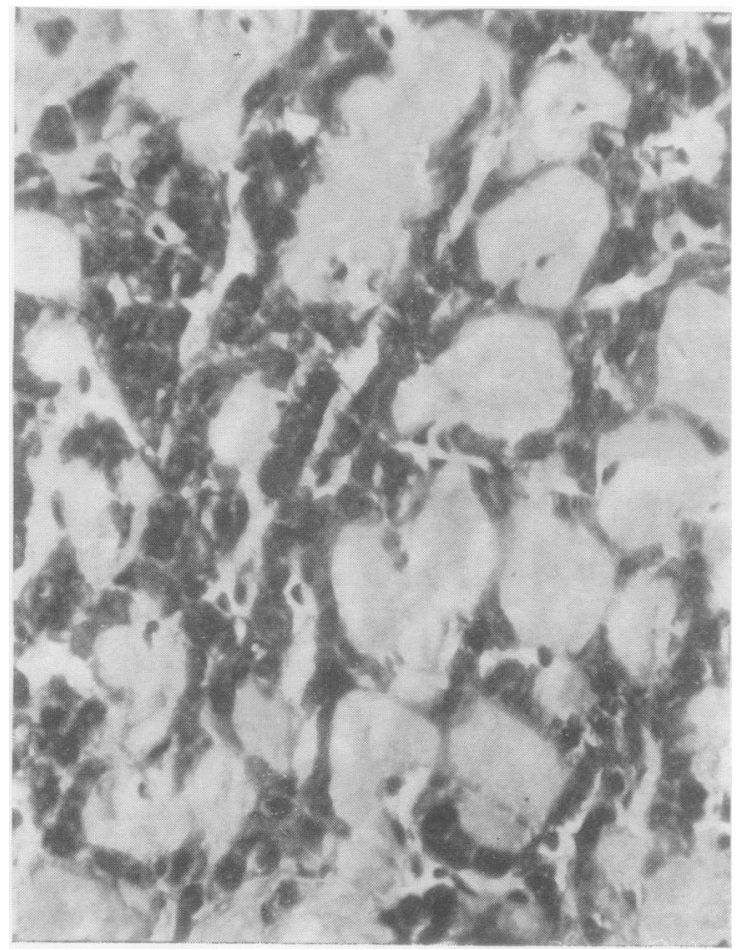

FIG. 18. Secondary amyloidosis. The liver cell columns are compressed by pale-staining amorphous tissue. Stained haematoxylin and eosin $\times 275$. advantage of positive diagnosis.

Secondary amyloidosis is shown by the deposition $\underset{\vec{F}}{\vec{\rho}}$ of amorphous pink-staining material between the sinusoids and the liver cell columns, which are $\frac{}{0}$ narrowed (Fig. 18). The nature of the material may be confirmed by methyl violet or Congo red stains. In the primary form the amyloid material is deposited in the walls of hepatic arterioles.

The liver from a patient with glycogen disease is $\overrightarrow{0}$ packed with glycogen but no more so than in many $\overrightarrow{\vec{H}}$ normal subjects. Increase in the stability of the ${ }_{\sigma}^{\omega}$ glycogen must also be shown. If possible, a portion of the biopsy, deep-frozen, should be sent to a centre. capable of performing enzyme studies on it.

CONGENITAL HEPATIC FIBRosis This condition is usually diagnosed in childhood and must be carefullyo distinguished from juvenile cirrhosis (Kerr, Harrison, Sherlock and Walker, 1961). The lobular structure isc intact but each lobule is surrounded by dense mature,

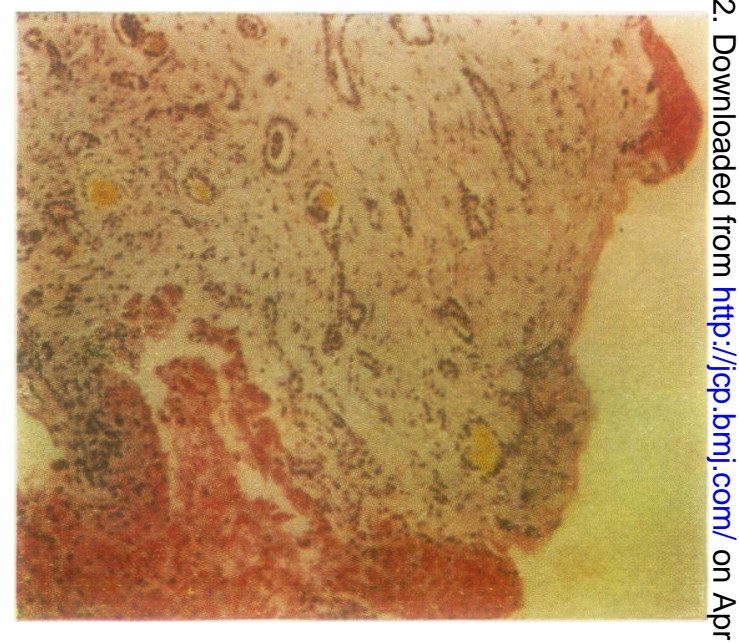

FIG. 19. Congenital hepatic fibrosis. The liver lobule is surrounded by a dense band of mature, avascular fibrous $\sigma$ tissue. The connective tissue band contains numerous bile $\mathrm{N}$ ducis, some of which contain bile. Portal vein radicles are $\mathrm{N}$ inconspicuous. Stained Best's carmine $\times 160$.

fibrous tissue in which bizarre-looking bile ducts are $\frac{0}{\bar{C}}$ prominent (Fig. 19). Portal vein radicules are difficult to find in the fibrous tissue bands and this ? hypoplasia may account for the portal hypertension 0 which can be a presenting feature. The condition in $\vec{D}$ some instances seems to be a variant of polycystic $\frac{?}{\mathbb{Q}}$ liver and the kidneys may occasionally also be involved.

The liver is so tough that needle biopsy may fail $\delta$ 


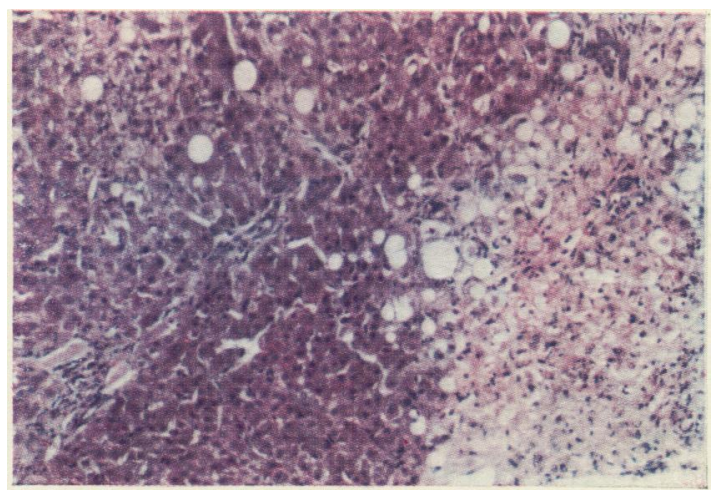

FIG. 20. Accidental carbon tetrachloride poisoning. To the right of the section liver cells are necrotic and show hydropic degeneration and fatty change. Surviving liver cells to the left of the section show occasional fatty change. The portal zones are unaffected.

or the sample may be so small that accurate diagnosis is impossible. In these circumstances open hepatic biopsy may be necessary.

\section{CHEMICAL LIVER INJURY}

The best example of chemical injury to the liver is poisoning by carbon tetrachloride which may be suicidal or accidental. In general, in all chemical poisonings the kidney suffers more than the liver and anuria is a greater risk than hepatic failure.

Liver biopsy in this group shows a centrizonal necrosis with hydropic change in the liver cells which show clear cytoplasm and pyknotic nuclei. Swelling of surrounding liver cells and fatty change is conspicuous. The portal zones are unaffected (Fig. 20). Cellular reaction is minimal in the early stages but later polymorphs may be found in relation to the centrizonal necrotic cells. The picture is quite different from infective hepatitis where the portal cellularity is conspicuous and fatty change is absent.

\section{NEEDLE LIVER BIOPSY IN CLINICAL RESEARCH}

Histochemical tenchiques have been particularly applied to various enzymes. For instance, nonspecific alkaline and acid phosphatase can be readily demonstrated in liver biopsy sections (Sherlock and Walshe, 1947; Barka, Schaffner, and Popper, 1961). Bile canaliculi may be beautifully shown by staining for adenosine triphosphatase and staining for glucose 6-phosphatase may be used in suspected glycogen disease (Wachstein, 1959). Electron microscopy is being increasingly used to show structural changes in liver biopsy material which are not obvious by light microscopy (Novikoff and Essner, 1960; Popper and Schaffner, 1961). Intracytoplasmic particles, perhaps the actual virus, have been shown in liver cells in infective hepatitis (Braunsteiner, Fellinger, Pakesch, Beyreder, Grabner, and Neumayr, 1957) and sinusoidal abnormalities also noted in the early stages of this condition (Cossel, 1959). Alterations in the microvilli lining the bile canaliculi have been seen in various forms of cholestatic jaundice including that produced by norethandrolone (Schaffner and Popper, 1959; Schaffner, Popper, and Perez, 1960). Electron microscopy may be useful in detecting abnormalities in pigment deposition within the liver in the siblings of patients with haemochromatosis (Scheuer and Williams, 1962).

Electron microscopy may be combined with histochemistry, the 'macromolecular cell pathology' of Novikoff and Essner (1960). Adenosine triphosphatase is localized to the microvilli of the canaliculi and 5-nucleotidase to the microvilli of the sinusoidal border (Popper and Schaffner, 1961). Acid phosphatase is found in Kupffer cells, degenerating foci, and regenerating nodules; alkaline phosphatase defines cholangioles (Novikoff and Essner, 1960). This so-called macromolecular method offers exciting possibilities for future research.

Quantitative analysis of liver biopsy specimens is made inaccurate by sampling difficulties and by failure to find a suitable standard of reference. In the liver with normal structure, results are reasonably reliable. For instance, the glycogen content of the diabetic liver has been shown to be normal (Hildes, Sherlock, and Walshe, 1949) and analysis of needle biopsy material gives a fair indication of the fat content of the diffusely fatty liver (Billing, Conlon, Hein, and Schiff, 1953). Difficulties arise, particularly in biopsies from cirrhotic livers where the proportion of fibrous tissue is uncertain. Chemical analysis for D.N.A., which is confined to the nucleus, probably represents the best reference base (Kosterlitz, 1958), although this may be valueless where the proportion of cells of different types is variable. Alternatively the substance being investigated may be referred to dry weight or to total nitrogen content of the biopsy.

Many quantitative studies of hepatic enzymes have been made on needle biopsy material. Waterlow (1958) has shown that in malnutrition cholinesterase was reduced in activity but other enzymes were well preserved. Nikkilä and Pitkänen (1959) have studied 14 enzymes in samples removed by needle biopsy from patients with thyrotoxicosis. Schmidt, Schmidt, and Wildhirt (1959) in Germany and Ryser, Frei, and Vannotti (1958) in Switzerland 
have also made extensive quantitative studies on hepatic enzymes in many disease states. Recently, Pitney and Onesti (1961) have described a method for the microbiological assay of vitamin $B_{12}$ and folic acid concentrations in needle biopsy specimens.

Although these results of microchemical analysis are of considerable interest, the problem of the sampling error has not been solved and in pathological liver biopsies this has, to date, afforded an insuperable obstacle to scientific progress.

I am greatly indebted to Professor K. R. Hill, to Dr. P. J. Scheuer, and to the technical staff of the Pathology Department of the Royal Free Hospital for much helpful advice. I wish also to thank Mr. R. R. Phillips and the staff of the Photographic Department for help with the illustrations.

\section{REFERENCES}

Amos, J. A. S., and Goodbody, R. A. (1959). Brit. J. Cancer. 13, 173. Anderson, P. J., and Popper, H. (1960). Amer. J. Path., 36. 483. Axenfeld, H., and Brass, K. (1942). Frankfurt. Z. Path., 57. 147.

Barka. T., Schaffner, F., and Popper, H. (1961). Lab. Invest., 10. 590

Baron, E. (1939). Arch. intern. Med., 63, 276

Becker, B. J. P., and Treurnich, D. S. F. (1959). Stain Technol., 34 261

Becker, V. (1961). Acta hapato-splenol. (Stuttg.), 8, 110.

Beckett, A. G., Livingstone, A. V., and Hill, K. R. (1961). Brit. med. J., 2, 1113

Billing, B. H., Conlon, H. J., Hein, D. E., and Schiff, L. (1953). J. clin. Invest., 32, 214.

Braunstein, H. (1956). A.M.A. Arch. Path., 62, 87.

Braunsteiner, H., Fellinger, K., Pakesch, F., Beyreder, J., Grabner, G., and Neumayr, A. (1957). Klin. Wischr., 35, 901.

Camain, R., Sénécal, J., and Couturier, P. (1956). Bull. Accid. nat. Med. (Paris), 140, 249.

Caroli, J., Mainguet, P., and Ricordeau, P. (1961). Gastroenterologia, 95, suppl. 94

Cohen, F. B., Robins, B., and Linstein, W. (1957). New Engl. J. Med., 257, 228

Cossel, L. (1959). Klin. W'schr., 37, 1263.

Dible, J. H., McMichael, J., and Sherlock, S. P. V. (1943). Lancet, 2. 402 .

Dubin, I. N. (1958). Amer. J. Med., 24, 268.

Federlin, K., and Sandritter, W. (1961). Munch. med. Wschr., 103. 803.

Fenster, L. F., and Klatskin, G. (1961). Amer. J. Med., 31, 328.

Fisher, C. J., and Faloon, W. W. (1958). Ibid., 25, 368.

Fogel, R., and Lewis, S. (1960). Ann. intern. Med., 53, 204.

Frerichs, F. T. von (1884). Über den Diabetes, Hirschwald, Berlin.

Gillman, T., and Gillman J. (1945). S. Afr. J. med. Sci., 10, 53.

Healey, R. J., Leff, A. H., and Rosenak, B. D. (1959). Amer. J. dig. Dis., 4 ns, 638

Hildes, J. A., Sherlock. S., and Walshe, V. (1949). Clin. Sci., 7, 287

Hoak, J. C., and Carter, J. R. (1961). Arch. intern. Med. (Chicago), 107,715 .

Hong, R., and Schubert, W. K. (1960). Amer. J. Dis. Child., 100, 42.

Huard, P., May, J. M., and Joyeux, B. (1935). Aln. Anat. path. Anat. norm. méd-chir., 12, 1118

Iversen, P., and Roholm, K. (1939). Acta Ired. scand., 102, 1.

Jame's, D. G. (1961). Amer. Rev. resp. Dis., 84, No. 5, Pt. 2, p. 14

Kalk, H., and Wildhirt, E. (1962). Lehrbuch und Atlas der Laparoskopic und Leberpunktion. Thieme, Stuttgart.

Kaye, R., Koop, C. E., Wagner, B. M. Picou, D., and Yakovac, W. C. (1959). Amer. I. Dis. Child.. 98, 699.

Kerr, D. N. S., Harrison, C. V., Sherlock, S., and Walker, R. M. (1961). Quart. J. Med., 30.91.
Korn, R. J., Kellow, W. F., Heller, P., Chomet, B., and Zimmerman, H. J. (1959). Amer. J. Med., 27, 60.

Kosterlitz, H. W. (1958). In Liver Function: A Symposium edited by R. W. Brauer. American Institute of Biological Sciences, Publ. No. 4. Washington, D.C.

Krarup. N. B., and Roholm, K. (1941). Klin. Wischr., 20, 193.

Levitan, R., Diamond, H. D.. and Craver. L. F. (1961). Amer. J. Me'd. 30. 99.

Liechty, R. D. (1958). A.M.A. Arch. Surg., 77. 780

Lucatello, L. (1895). Lavori del Congressi di Medicina Interna, Rome. p. 327

Mackay, I. R. (1961). Gastroenterology, 40.617.

Madden. R. E. (1961). Arch. Surg. (Chicago), 83. 778

Meneghello, J., Espinoza, J., and Coronel, L. (1949). Am'r. J. Dis. $\vec{O}$ ( hild., 78, 141 .

Menghini. G. (1958). Gastroenterology, 35, 190.

Nelson, R. S., and Salvador, D. S. J. (1960). Ann. intern. M('d.. 53, O 179

Nikkilä. E. A., and Pitkänen, E. (1959). Acta endocr. (Kh/ .), 31, 57

Norris, T. St. M., Singh, M. M., and Montuschi, E. (1958). Lance', 2, 560

Novikoff, A. B., and Essner, E. (1960), Amer, J. Med, 29, 102

Ostertag. H. (1950). Z. Hyg. Infekt.-Kr., 131, 482.

Parets, A. D. (1959). Amer. J. med. Sci., 237, 335

Parsons, R. J., and Zarafonetis, C. J. D. (1945) Arch intern. Med. 75.1 .

Pitney, W. R., and Onesti, P. (1961). Aust. J. exp. Biol. mo'd. Sci., 39. 7.

Popper, H., Rubin, E., Krus, S.. and Schaffner, F. (1960). Gastroenterologir, 39. 669.

Hill. New York. - (1959). J. amer. med. Ass., 169. 1447. - (1961). Progress in Liver Dise'ase's, Vol. 1. Grune \& Stratton, Philadelphia.

Read, A. E.. Harrison, C. V., and Sherlock, S. (1961). Amer. J. Med. 31. 249.

Report of the Board for Classification and Nomenclature of Cirrhosis of the Liver (1956). Gastroenterologv, 31, 213

Ryser, H., Frei, J., and Vannotti, A. (1958). Clin. chim. Acta, 3, 486. ำ

Samuelsson, S., and Sjöstedt, S. (1961). Acta med scand 170,627.

Schaffner, F. and Popper, H. (1959). Gastroenterology, 37, 565.

- _.... and Chesrow, E. (1959). Amer. J. Med., 26, 249.

- - - and Perez, V. (1960). J. Lcib. clin. Med., 56, 623

Scheuer, P. J., and Williams, R. (1962). J. Path. Bact., in press.

Schiff, L. (1951). Ann. intern. Med., 34, 948.

Schmidt, E. Schmidt, F. W., and Wildhirt, E. (1959). Klin. Uschu 37. 1221.

Shaldon, S., and Sherlock, S. (1957). Brit. med. J., 2, 734. (1962). Lancet, 1, 63.

Sherlock, S. (1945). Ibid., 2, 397.

- (1958). Diseases of the Liver and Biliary. System, 2nd ed. Blackwell, Oxford

- (1959). Gastroenterclogy, 37. 574

- - and Walshe, V. (1947). J. Path. Bact., 59, 615

Singh, A., Jolly, S. S., and Singh, S. (1960). A.M.A. Arch. intern. med 105,424

Stauffer, M. H., Gross, J. B., Foulk, W. T., and Dahlin, D. C. (1961) Gastroenterology, 41, 92.

Terry, R. (1952). Brit. med. J., 1, 1102.

Terry, R. B. (1954). J. Amer. med. Ass., 154, 990.

Thaler, H. (1958). Wien klin. Wschr., 70, 622

Uzman, L. L. (1957). A.M.A. Arch. Path., 64, 464

Volwiler, W., and Jones, C. M. (1947). New Eng!. J Med. 237.651 (S)

Wachstein, M. (1959). Gastroenterology, 37, 525.

Ward, J. R., and Hunter, R. C. (1958). Ann. intern. Med., 48, 157.

Ward, J., Schiff, L., Young, P., and Gall, E. A. (1954). Gastroenterde $\log 1,27,300$.

Waterlow, J. C. (1948). Spec. Rep. Ser. med. Re's. Comn. (Lond. ID No. 263.

- (1958). W. Indian med, J., 7, 44

Williams, R., Scheuer. P. J., and Sherlock, S. (1962). Quart. J. Med. in press.

Zamcheck. N., and Klausenstock, O. (1953). New Engl. J. Med., 249 1062 .

- - and Sidman, R. L. (1953). Ibid., 249, 1020

Zimmerman, H. J., Chomet, B., Kulesh. M. H., and McWhorter C. A. (1961). Arch. intern. Med. (Chicago), 107, 494. 